\title{
Association of Microalbuminuria and IL-6, ET-1 and NO in Patients with Essential Hypertension
}

\section{Yuan Wang1 1 , Jianhui Tian², Yongchen Sun'1, Xiaxia Wang²}

\author{
${ }^{1}$ Qingdao University, Qingdao 266071, China; \\ ${ }^{2}$ Affiliated hospital of Qingdao University, Qingdao 266003, China
}

\begin{abstract}
Objective: Research had shown that hypertension was the main risk factor for coronary heart disease (CHD). Hypertension with microalbuminuria (MAU) is the important mark of target organ damage and endothelial function impaired, and also the independent factor for CHD. This paper aimed to explore the mechanism that patients with hypertension combined MAU increased the risk of CHD by investigating the relationship between MAU and IL-6, ET-1, NO in patients with essential hypertension (EH).

Methods: To select 132 patients with essential hypertension who were hospitalized in the affiliated hospital of Qingdao university from October 2014 to July 2015. According to the MAU levels, there were 2 experimental groups in this experiment: MAU positive group (MAU>30 mg/l) and MAU negative group (MAU<30 mg/l). And 50 healthy persons in physical examination center of the same hospital were selected as a normal control group. All patients were performed blood routine, urinary routine, stool routine and biochemical analysis. IL-6 level and ET-1 level were measured by enzyme-linked immunosorbent assay. NO level was determined by nitrate reductase method. Statistical analysis was performed by SPSS version 19.0.

Results: The serum IL-6 (103.45 $\pm 4.89 \mathrm{pg} / \mathrm{ml})$, ET-1 $(209.62 \pm 5.00 \mathrm{pg} / \mathrm{ml})$ and systolic blood pressure $(174.59 \pm 25.75 \mathrm{mmHg})$ levels in MAU positive group were obviously higher than that in the MAU negative group. The difference was statistically significant $(\mathrm{P}<0.05)$. The serum NO level $(19.76 \pm 2.48$ umol/l) in MAU positive group was significantly lower than that in the MAU negative group. The difference was statistically significant $(\mathrm{P}<0.05)$. The multi-factor regression analysis showed that the IL-6 $(\mathrm{B}=0.206, \mathrm{p}=0.021), \mathrm{ET}-1(\mathrm{~B}=0.594, \mathrm{p}<0.01)$, were positively correlated to MAU, while $\mathrm{NO}(\mathrm{B}=-0.380, \mathrm{p}=0.012)$ was negatively correlated to MAU.
\end{abstract}

Conclusion:

(1) The levels of IL-6 and ET-1 in hypertensive patients with MAU increased significantly, and the NO level decreased.

(2) IL-6, ET-1 were positively correlated to MAU, while NO was negatively correlated to MAU.

(3) Hypertension with MAU has important clinical significance. It needs more attention and effective management.

Keywords: Essential hypertension, Microalbuminuria, Interleukin-6, Endothelin-1, Nitric Oxide, Coronary heart disease

\section{Introduction}

With the improvement of living standard and the change of our lifestyle, there is a growth trend to the incidence of CHD. The risk factors of coronary heart disease have attracted people's attention. The microalbuminuria is a sensitive indicator of vascular endothelial damage, as well as an independent risk factor of coronary heart disease (CHD) [1]. Inflammatory substances took essential part in this progress [2-4]. IL- 6, ET-1 and NO were considered to be the important inflammatory factors in the vascular endothelial injury. This paper aimed to explore the mechanism that hypertensive patients with MAU increased the risk of CHD by investigating the relationship between MAU and IL-6, ET-1, NO in patients with essential hypertension $(\mathrm{EH})$, which could guide the primary prevention of coronary heart disease.

\section{Patients}

To select 132 patients with essential hypertension who were hospitalized in the affiliated hospital of Qingdao university from October 2014 to July 2015. According to the 1999 World Health Organization and the International Hypertension Society (WHO/ISH) diagnostic criteria, essential

This article is published under the terms of the Creative Commons Attribution License 4.0 Author(s) retain the copyright of this article. Publication rights with Alkhaer Publications. Published at: http://www.ijsciences.com/pub/issue/2016-04/

DOI: 10.18483/ijSci.1006; Online ISSN: 2305-3925; Print ISSN: 2410-4477 
hypertension was diagnosed. There were two experimental groups: The MAU positive group in which the MAU level was higher than $30 \mathrm{mg} / \mathrm{l}$ and the MAU negative group in which the MAU level was lower than $30 \mathrm{mg} / \mathrm{l}$. And 50 healthy persons in physical examination center of the same hospital were selected as a normal control group. The following conditions were excluded: secondary hypertension, severe hepatic and renal dysfunction, malnutrition, malignant tumor, malignant anemia, coronary heart disease, heart failure, diabetes and infectious diseases.

\section{Laboratory analysis}

Patients with hypertension avoided strenuous activity at night. Collect pollution-free urine $10 \mathrm{ml}$ as specimens and detect immediately the next morning. The samples were centrifuged at $3000 \mathrm{r} / \mathrm{min}$ for 15 minutes and got the supernatant to measure MAU by immune turbidimetry. Blood samples were extracted about $5 \mathrm{ml}$ from elbow venous blood in the morning, then centrifuged at $4^{\circ} \mathrm{C} 3000 \mathrm{r} / \mathrm{min}$ for 15 minutes and the supernatant were stored at -80 degrees centigrade until assayed. IL-6 level and ET-1 level were measured by enzyme-linked immunosorbent assay. NO level was determined by nitrate reductase method. All patients were performed blood routine, urinary routine, stool routine and biochemical analyze.

\section{Statistics}

All experimental data which conformed to normal distribution were reported as the mean \pm SD ( $\bar{x} \pm s)$. Statistical analysis was performed by SPSS version 19.0. The comparison of basic data and IL-6, ET-1, NO used single factor analysis of variance. Regression analysis used multi-factor regression analysis.

\section{Results}

Basic data and IL-6, ET-1, NO results are shown in Table1, 2. There were no differences in age, BMI, glucose, totalcholesterol, triglycerides, LDL cholesterol, serumurea nitrogen, uric acid, creatinine, serum total bilirubin and diastolic pressure. The serum IL-6, ET-1 and systolic blood pressure levels in MAU positive group were obviously higher than that in the MAU negative group. The difference was statistically significant $(\mathrm{P}<0.05)$. The serum NO level $(19.76 \pm 2.48 \mathrm{umol} / \mathrm{l})$ in MAU positive group was significantly lower than that in the MAU negative group. The difference was statistically significant $(\mathrm{P}<0.05)$.

Table 1 Baseline characteristics of three groups

\begin{tabular}{llcl}
\hline Clinical data & \multicolumn{1}{c}{$\begin{array}{c}\text { MAU positive group } \\
\mathrm{n}=47\end{array}$} & $\begin{array}{c}\text { MAU negative group } \\
\mathrm{n}=85\end{array}$ & $\begin{array}{c}\text { Normal control group } \\
n=50\end{array}$ \\
\hline Age (years) & $51.23 \pm 13.28$ & $50.78 \pm 12.51$ & $50.96 \pm 15.47$ \\
BMI $\left(\mathrm{kg} / \mathrm{m}^{2}\right)$ & $25.98 \pm 3.64$ & $24.58 \pm 4.12$ & $25.45 \pm 3.85$ \\
Glucose $(\mathrm{mmol} / \mathrm{L})$ & $5.22 \pm 1.15$ & $5.27 \pm 0.91$ & $5.12 \pm 1.23$ \\
Total cholesterol(mmol/l) & $4.46 \pm 1.28$ & $4.53 \pm 0.69$ & $4.36 \pm 1.21$ \\
Triglycerides(mmol/l) & $1.54 \pm 0.98$ & $1.52 \pm 1.15$ & $1.48 \pm 1.02$ \\
LDL cholesterol (mmol/l) & $2.54 \pm 0.86$ & $2.49 \pm 1.02$ & $2.35 \pm 0.56$ \\
Serum urea nitrogen (mmol/l) & $5.67 \pm 1.42$ & $5.59 \pm 1.36$ & $5.68 \pm 1.32$ \\
Uric Acid (umol/L) & $305.36 \pm 79.69$ & $302.58 \pm 81.57$ & $295.84 \pm 80.54$ \\
Creatinine (umol/L) & $88.92 \pm 14.25$ & $90.86 \pm 13.85$ & $89.64 \pm 14.06$ \\
Serumtotalbilirubin $(\mathrm{umol} / \mathrm{L})$ & $13.85 \pm 5.27$ & $14.52 \pm 4.42$ & $13.26 \pm 5.26$ \\
Systolic pressure $(\mathrm{mmHg})$ & $174.59 \pm 25.75^{\mathrm{ab}}$ & $155.62 \pm 23.84^{\mathrm{a}}$ & $115.23 \pm 12.45$ \\
Diastolic pressure $(\mathrm{mmHg})$ & $106.52 \pm 18.74$ & $101.36 \pm 16.25$ & $76.36 \pm 10.52$ \\
\hline
\end{tabular}

$\mathrm{a} p<0.05$, compared with MAU positive group, $\mathrm{b} p<0.05$, compared with MAU negative group. 
Table 2 The comparison of three groups of IL-6,ET-1and NO

\begin{tabular}{lcccc}
\hline \multicolumn{1}{c}{ Group } & $\mathrm{n}$ & $\mathrm{IL}-6(\mathrm{pg} / \mathrm{ml})$ & $\mathrm{ET}-1(\mathrm{pg} / \mathrm{ml})$ & $\mathrm{NO}(\mathrm{umol} / \mathrm{l})$ \\
\hline $\begin{array}{l}\text { Normal control group } \\
(5.74 \pm 4.62 \mathrm{mg} / \mathrm{l})\end{array}$ & 50 & $41.48 \pm 4.16$ & $91.35 \pm 4.53$ & $64.96 \pm 4.61$ \\
$\begin{array}{l}\text { MAU negative group } \\
(10.75 \pm 7.39 \mathrm{mg} / \mathrm{l})\end{array}$ & 85 & $74.05 \pm 4.06^{\mathrm{a}}$ & $165.17 \pm 6.01^{\mathrm{a}}$ & $36.53 \pm 4.89^{\mathrm{a}}$ \\
$\begin{array}{l}\text { MAU positive group } \\
(56.72 \pm 12.65 \mathrm{mg} / \mathrm{l})\end{array}$ & 47 & $103.45 \pm 4.89^{\mathrm{ab}}$ & $209.62 \pm 5.00^{\mathrm{ab}}$ & $19.76 \pm 2.48^{\mathrm{ab}}$ \\
\hline
\end{tabular}

a $p<0.05$, compared with MAU positive group, $\mathrm{b} p<0.05$, compared with MAU negative group.

The results of multi-factor regression analysis are shown in Table3. The serum IL-6(B=0.206, $\mathrm{p}=0.021)$, ET$1(\mathrm{~B}=0.594, \mathrm{p}<0.01)$ were positively correlated to MAU, while $\mathrm{NO}(\mathrm{B}=-0.380, \mathrm{p}=0.012)$ was negatively correlated to MAU.

Table 3 Multi-factor regression analysis of IL-6,ET-1,NO

\begin{tabular}{cccc}
\hline & IL-6 & ET-1 & NO \\
\hline B & 0.206 & 0.594 & -0.380 \\
$\mathrm{t}$ & 2.622 & 8.715 & -2.938 \\
$\mathrm{p}$ & 0.021 & $<0.01$ & 0.012 \\
\hline
\end{tabular}

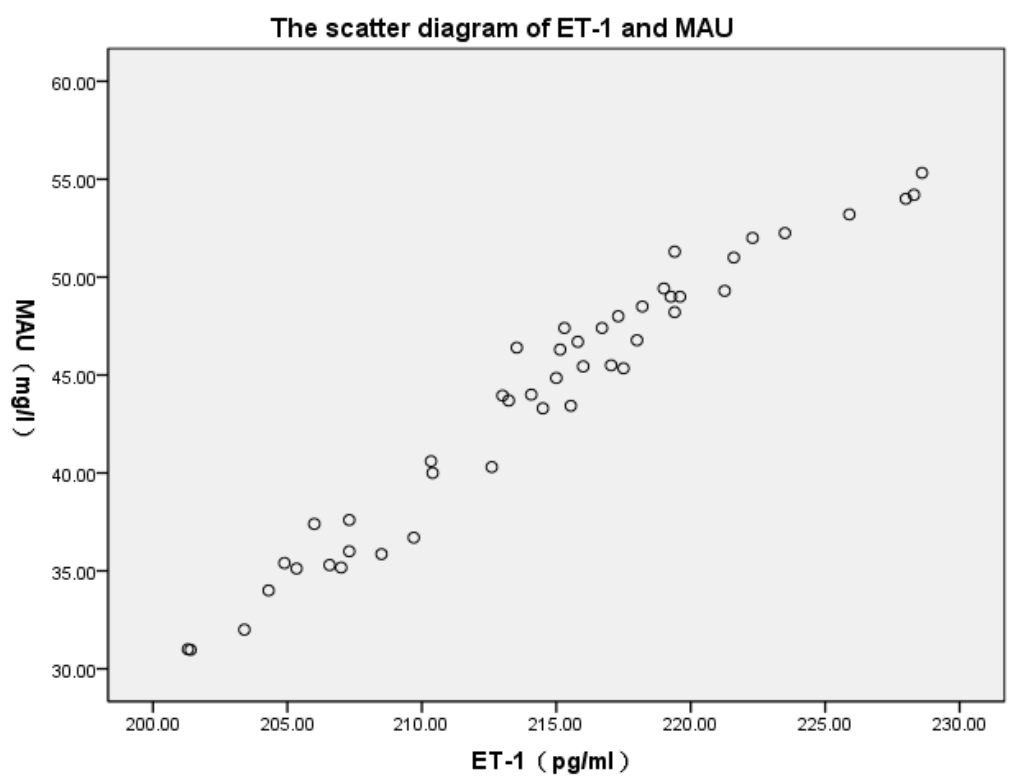



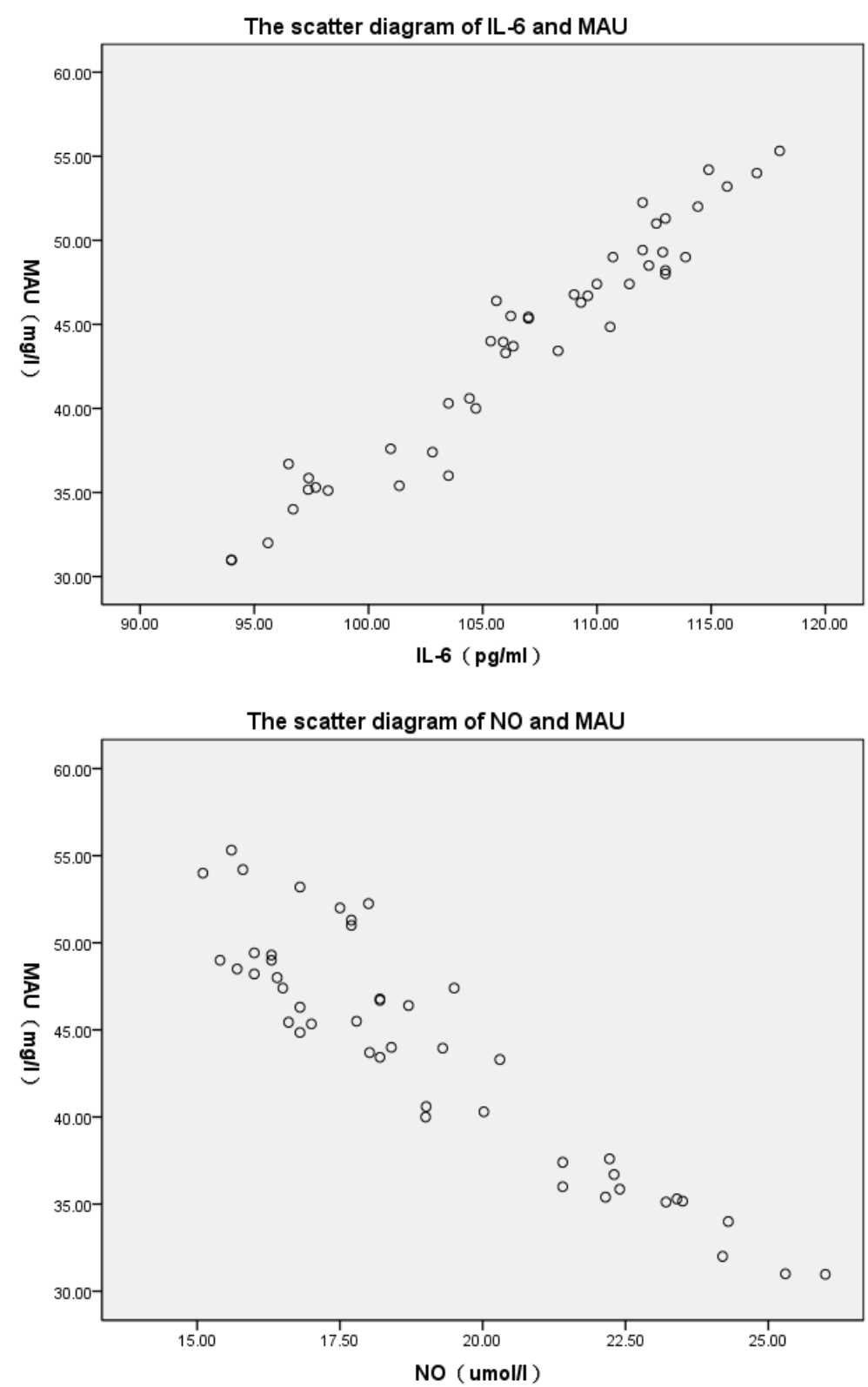

\section{Discussion}

Research had shown that MAU was the independent risk factor of coronary heart disease [5]. In the late 1980s, scholars had put forward that the MAU was a sign of widespread damage to blood vessels [6]. Albumin is about $7.2 \mathrm{~nm}$ in diameter. Usually, it hardly goes through the glomerular basement membrane in healthy body. So the urine albumin excretion rate of healthy adults is very low. Any reason that causes the glomerular basement membrane injured and enhances the permeability could increase the elimination of albumin. Foreign studies [7, 8] had confirmed that the endothelial function was impaired, the extracellular matrix changed, the vascular permeability increased and lipid material discharged into the blood vessel walls in patients with MAU. Finally, the occurrence of atherosclerosis and CHD was increased [9]. However, the mechanism that hypertensive patients with MAU increased the risk of CHD is unclear. Some mechanisms such as vascular endothelial dysfunction, inflammatory reaction were accepted widely.

As an inflammatory factor, IL-6 was secreted by many cells in the body. This study found that the serum IL-6 level in hypertensive patients with MAU was significantly higher than the patients without MAU. Multi-factor regression analysis showed that IL-6 was an influential factor of MAU and IL-6 was positively correlated to MAU, which prompted that IL-6 had a close relationship with MAU and the level of IL-6 in hypertension combined MAU patients was significantly increased. Studies had shown that IL-6, as an inflammatory cytokines of CHD [10-12], could cause damage to the body by various mechanisms [13, 14]. Firstly, IL-6 could stimulate the proliferation of 
smooth muscle cell, affect lipid intake and metabolism and participate in the formation of atherosclerosis. Secondly, because of the vascular smooth muscle cell proliferation, the vascular wall became stiffness and the peripheral circulation resistance increased and then the blood pressure raised, which could accelerate the progression of atherosclerosis [15]. Wang $\mathrm{K}$ et al. showed that interleukin-6 gene polymorphisms were the risk factor of CHD [16]. Over all, the increased IL-6 level in hypertensive patients with MAU could lead to the inflammatory reaction enhancement, vascular endothelial dysfunction and vascular atherosclerosis progress aggravation. Eventually, CHD occurred. Patients with hypertension without MAU had lower IL-6 level, mild inflammatory reaction, relatively well endothelial function and then lower risk of CHD relatively. Therefore, IL-6 plays an important role in the occurrence of $\mathrm{CHD}$ caused by hypertension combined MAU. Hypertension with MAU is an important symbol that can increase the risk of CHD incidence.

ET-1, an important inflammatory factor, was mainly generated by vascular endothelial cells. It was also the strongest shrink blood vessels material [17] which had been discovered until now. NO was produced from L-arginine in vascular endothelial cell under the catalytic through Carbon monoxide synthase (NOS) $[18,19]$. NO is a vital inflammatory mediator in our body. This study found that the serum ET-1 level in hypertensive patients with MAU was significantly higher than the patients without MAU while the serum NO level in hypertensive patients with MAU were significantly lower than the patients without MAU. Multi-factor regression analysis showed that ET-1 and NO were influential factors of MAU. ET-1 was positively correlated to MAU while NO was negatively correlated to MAU. It prompted that ET-1 and NO had a close relationship with MAU and they all played important roles in the formation of MAU.

NO and ET-1 are important vascular active substances which represented diastolic and systolic substance respectively to maintain the tension of vascular [20]. ET-1 is a kind of promoting mitosis substance that can promote vascular smooth muscle cell proliferation and aggravate atherosclerosis. NO has many functions: Firstly, as a vasomotor cytokine, it can dilate blood vessels. Secondly, it could inhibit platelet aggregation and adhesion in order to reduce thrombosis and atherosclerosis, thus reducing the risk of cardiovascular disease [21]. Thirdly, NO could regulate smooth muscle proliferation [22] while ET-1 has the opposite function. In this way, NO was regarded as the inhibitor of atherosclerosis plaque formation [23]. High ET-1 level can induce vascular endothelial dysfunction and NO synthesis. Wedgwood [24] found that ET-1 could reduce the activity of Nitric oxide synthetic protein gene and decrease the formation of NO. Therefore, ET-1 and $\mathrm{NO}$ has an inseparable relationship in restraining each other and play a crucial role in the process of hypertension and CHD development. This study also found that the ET-1 level in hypertensive patients with MAU increased and the NO level decreased. The inflammatory reaction enhanced while antiinflammatory response decreased. The vascular endothelial dysfunction and vascular atherosclerosis progress aggravation increased the incidence of CHD.

Above all, the levels of IL-6 and ET-1 in hypertensive patients with MAU increased and the NO level decreased. It indicated that the inflammatory reaction enhanced obviously in the body and endothelial function was impaired which can cause arterial vascular sclerosis and increase the risk of CHD. Therefore, hypertension with MAU is a dangerous sign of CHD. Although other people have researched hypertension and $\mathrm{CHD}$, but this paper aimed to research the mechanism that hypertensive patients with MAU increased the risk of CHD by investigating the relationship between MAU and IL-6, ET-1, NO in patients with essential hypertension. It also confirmed that hypertension combined MAU was the independent factor for CHD. MAU is the important symbol of CHD incidence. It needs more attention and effective management. Positive and effective blood pressure level control and MAU occurrence reduction has great significance in CHD prevention.

\section{References}

1) Klausen K, Borch-Johnsen K, Feldt-Rasmussen B, et al. Very low levels of microalbuminuria are associated with increased risk of coronary heart disease and death independently of renal function, hypertension, and diabetes. Circulation 2004; 110:32-5.

2) Enayati S, Seifirad S, Amiri $P$, et al. Interleukin-1 beta, interferon-gamma, and tumor necrosis factor-alpha gene expression in peripheral blood mononuclear cells of patients with coronary artery disease. ARYA atherosclerosis, 2015, 11(5): 267

3) Al Shahi H, Shimada K, Miyauchi K et al. Elevated Circulating Levels of Inflammatory Markers in Patients with Acute Coronary Syndrome.Int J Vasc Med, 2015,805375.

4) Mahalle N, Garg M, Kulkarni M et al. Association of Inflammatory Cytokines with Traditional and Nontraditional Cardiovascular Risk Factors in Indians with known Coronary Artery Disease. Ann Med Health Sci Res, 2014, 4(5):706-712.

5) Mahfoud F, Ukena C, Poss J, et al. Microalbuminuria independently correlates to cardiovascular comorbidity burden in patients with hypertension. Clin Res Cardiol, 2012, 101(9):761-766.

6) DeckertT, Feldt-RasmussenB, Borch-Johnsenk, et al.Albuminuria refectswidespread vascular damage. The Steno hypothesis.Diabetologia, 1989, 32(4):219-26.

7) HoseiniVN, Rasouli M. Microalbuminuria correlates with thePrevalenceandseverityofcoronaryarterydiseaseinnondiabeticpatients.Cardiol, 2009, 16(2):142-145.

8) Ekicibasi E,Kaderli AA, Kazazoglu AR, et al. Association of Microalbuminuriaandfasting insulin levels withpresenceandSeverity of coronary artery disease innondiabetic cases.AnadoluKardiyolDerg,2008,8(1):16-21. 
9) Oliveras A, Armario P, Sierra C et al. Urinary albumin excretion at follow-up predicts cardiovascular outcomes in subjects with resistant hypertension. Am J Hypertens, 2013, 26(9):1148-1154.

10) Hou H, Wang C, Sun F, et al. Association of interleukin-6 gene polymorphism with coronary artery disease: an updated systematic review and cumulative meta-analysis.Inflamm Res, 2015, 64(9):707-720.

11) Liu SL, Yin YW, Sun QQ et al. Genetic polymorphisms of interleukin-6 gene and susceptibility to coronary artery disease in Chinese population: Evidence based on 4582 subjects.Hum Immunol, 2015,76(7):505-510.

12) Caselli C, De Graaf MA, Lorenzoni et al. VHDL cholesterol, leptin and interleukin-6 predict high risk coronary anatomy assessed by $\mathrm{CT}$ angiography in patients with stable chest pain. Atherosclerosis, 2015, 241(1):55-61.

13) Kim KI, Lee JH, Chang HJ, et al. Association between blood pressure variability and inflammatory marker in hypertensive patient. Circulation,2008,72(2):293-298.

14) Gigante B, Strawbridge RJ, Velasquez IM et al. Analysis of the role of interleukin 6 receptor haplotypes in the regulation of circulating levels of inflammatory biomarkers and risk of coronary heart disease.PLoS One, 2015,10(3):e0119980.

15) Boutouyrie P, Tropeano AI, Asmar R, et al. Aortic stiffness is an independent predictor of primary coronary events in hypertensive patients: a longitudinal study. Hypertension 2002, 39(1):10-5

16) Wang K, Dong PS, Zhang HF et al. Role of interleukin-6 gene polymorphisms in the risk of coronary artery disease [J].Genet Mol Res, 2015,14(2):3177-3183.

17) John R, Vane FRS, Erik E. Regulatory function of the vascular endothelium. The New England Tournal of Medicine, 1990, 323(1):27-36.

18) Funchgott RF, Zawadski JV. The obligatory role of endothelial cell in the relaxation of arterial smooth muscle by acetylcho line.Nature,1980, 288:373.

19) Mukai Y, Sato S. Polyphenol-containing azuki bean (Vigna angn-laris) extract attenuates blood pressure elevation and modulates nitric oxide synthase and caveolin-1 expressions in rats with hypertension.Nutr Metab Cardiovasc Dis. 2009,19(7):491-497.

20) Berényiová A, Kristek F, Drobná M,et al. Role of NO signaling pathway in regulation of vascular tone--new aspects. Cesk Fysiol, 2015,64(1):4-11.

21) Freitag DF, Butterworth AS, Willeit $P$ et al. Cardiometabolic effects of genetic upregulation of the interleukin 1 receptor antagonist: a Mendelian randomisation analysis.Lancet Diabetes Endocrinol, 2015, 3(4):243-253.

22) Colombo MG, Paradossi U, Andreassi MG, Botto N, et al. Endothelial nitric oxide synthase gene polymorphisms and risk of coronary artery disease. Clin Chem 2003, 49(3): 389395.

23) Colombo MG, Andreassi MG, Paradossi U, Botto N, et al. Evidence for association of a common variant of the endothelial nitric oxide synthase gene (Glu298- Asp polymorphism) to the presence, extent, and severity of coronary artery disease. Heart, 2002, 87(6): 525-528.

24) Wedgwood S, Black SM . Endothelin-1 decreases endothelial NOS expression and activity through $\mathrm{ET}_{\mathrm{A}}$ receptor mediated generation of hydrogen peroxide. Am J Physiol Lung Cell Mol Physiol, 2005, 288(3):L480-L487. 